\title{
A Role for Dopamine D1 Receptors of the Nucleus Accumbens Shell in Conditioned Taste Aversion Learning
}

\author{
Sandro Fenu, Valentina Bassareo, and Gaetano Di Chiara \\ Department of Toxicology and Consiglio Nazionale delle Ricerche, Center for Neuropharmacology, University of Cagliari, \\ 09126 Cagliari, Italy
}

\begin{abstract}
The involvement of dopamine (DA) in conditioned taste aversion (CTA) learning was studied with saccharin or sucrose as the conditioned stimulus (CS) and intraperitoneal lithium as the unconditioned stimulus (US). The dopamine $\mathrm{D}_{1}$ antagonist $R(+)-7-$ chloro-8-hydroxy-3-methyl-1-phenyl-2,3,4,5-tetrahydro-1H-3benzazepine hydrochloride (SCH 23390) (12.5-50 $\mu \mathrm{g} / \mathrm{kg}$, s.c.), given 5 min after the CS, impaired the acquisition of CTA in a paradigm consisting of three or a single CS-lithium association. SCH 23390 failed to impair CTA acquisition given 45 min after, 30 min before, or right before the CS. (-)-trans-6,7,7a,8,9,13bhexahydro-3-chloro-2-hydroxy- $N$-methyl-5a-benzo-(D)-naphtho(2,1b) azepine (SCH 39166) (12.5-50.0 $\mu \mathrm{g} / \mathrm{kg}$, s.c), a SCH 23390 analog that does not bind to $5 \mathrm{HT}_{2}$ receptors, also impaired CTA. No significant impairment of CTA was obtained after administration of the specific $D_{2} / D_{3}$ antagonist raclopride (100 and 300
\end{abstract}

$\mu \mathrm{g} / \mathrm{kg}$, s.c.). The ability of SCH 23390 to impair CTA learning was confirmed by its ability to reduce the conditional aversive reactions to a gustatory CS (sweet chocolate) as estimated in a taste reactivity paradigm. SCH 39166 impaired CTA also when infused in the nucleus accumbens (NAc) shell 5 min after the CS. No impairment was obtained from the NAc core or from the bed nucleus stria terminalis. The results indicate that $D_{1}$ receptor blockade impairs CTA learning by disrupting the formation of a short-term memory trace of the gustatory CS and that endogenous dopamine acting on $D_{1}$ receptors in the NAc shell plays a role in short-term memory processes related to associative gustatory learning.

Key words: dopamine; $D_{1}$ receptors; nucleus accumbens shell; conditioned taste aversion; short-term memory; $\mathrm{SCH}$ 23390; SCH 39166; lithium chloride
Organisms have the unique property of emitting responses or performing actions finalized to their survival and to the survival of their species (Bindra, 1974; Epstein, 1982; Toates, 1986). This general process of motivation can be envisioned to start with the evolutionary assignment of motivational valence (positive or negative) to certain stimuli (primary motivational stimuli). Positive (appetitive) stimuli are innately capable of promoting approach, contact, and consumption of the object stimulus; negative (aversive) stimuli, however, elicit reactions intended to avoid or terminate the stimulus. Drive state can affect the motivational properties of stimuli, increasing or decreasing it; learning, on the other hand, can assign a specific motivational valence to otherwise neutral stimuli or change that of primary ones (Toates, 1986).

Since the early observations of a loss of dopamine (DA) in the putamen of Parkinsonian patients (Ehringer and Hornykiewicz, 1960) and the view (Mogenson et al., 1980) of the ventral striatum as an interface between motivation and action, DA has been traditionally involved in the expression of motivated behavior. Accordingly, DA has been attributed different roles, activational (Salamone, 1988), sensory-motor (Marshall and Teitelbaum, 1977; Salamone, 1992), incentive-motivational (Wise, 1982; Berridge and Robinson, 1998), all related to response expression. A role of DA in response expression, however, has always plagued

\footnotetext{
Received April 16, 2001; revised June 1, 2001; accepted June 11, 2001.

This work was performed with funds from Ministero dell'Università della Ricerca Scientifica e Tecnologica (40 and 60\%) and from Consiglio Nazionale delle Ricerche (Center for Neuropharmacology). We thank Dr. Elio Acquas for help with the statistics.

Correspondence should be addressed to Prof. Gaetano Di Chiara, Dipartimento di Tossicologia, Viale A. Diaz 182, 09126 Cagliari, Italy. E-mail: diptoss@tin.it. Copyright (C) 2001 Society for Neuroscience $0270-6474 / 01 / 216897-08 \$ 15.00 / 0$
}

any effort to demonstrate a role of DA in the acquisition of motivation.

In principle a role of DA in this process might derive from its involvement in the hedonic properties of rewards (Wise et al., 1978) or in learning of the association between the stimuli and reward (Pavlovian learning), between responses and their outcome (instrumental learning), or between stimuli and responses (habit learning) (Mackintosh, 1983; Dickinson and Balleine, 1994). If the hypothesis of a role of DA in hedonia has been revised to include an incentive-motivational account (Wise, 1982), that of a role of DA in associative learning, while strongly advocated, is not supported by as strong evidence (Beninger, 1983; Di Chiara, 1995, 1999; Montague et al., 1996; Berridge and Robinson, 1998).

We have reported that $D_{1}$ receptor antagonists impair the acquisition of conditioned place preference as well as place aversion induced by a variety of drugs (Acquas et al., 1989; Acquas and Di Chiara, 1994). On this basis we hypothesized that DA, acting on $\mathrm{D}_{1}$ receptors, plays a role in appetitive as well as in aversive learning (Acquas and Di Chiara, 1994; Di Chiara, 1995). Conditioned taste aversion (CTA) (Garcia et al., 1955) is a form of Pavlovian learning whose peculiar property is that of allowing a long interval (up to $6 \mathrm{hr}$ ) for efficient association of the gustatory CS with the malaise-inducing US (Bûres et al., 1988; Yamamoto et al., 1994). These properties make CTA a unique paradigm for the study of the mechanism of action of $\mathrm{D}_{1}$ antagonists in associative learning. In the present study we have investigated the effect of systemic and intracerebral administration of the $\mathrm{D}_{1}$ antagonists $R(+)$-7-chloro-8-hydroxy-3-methyl-1-phenyl-2,3,4,5-tetrahydro-1H3-benzazepine hydrochloride ( $\mathrm{SCH} 23390)$ and (-)-trans6,7,7a,8,9,13b-hexahydro-3-chloro-2-hydroxy- $N$-methyl-5a-benzo- 
(D)-naphtho-(2,1b) azepine (SCH 39166) on the acquisition of CTA.

\section{MATERIALS AND METHODS}

\section{Animals}

Male Sprague Dawley rats (Charles River, Calco, Italy) weighing 250$275 \mathrm{gm}$ were used. All animals were individually housed in Plexiglas cages placed in a temperature- and humidity-controlled room with food and water ad libitum. Lights were on from 8:00 A.M. to 8:00 P.M. All experiments were performed in the home cage. Except for the tastereactivity experiments, in which rats had water ad libitum, in all CTA experiments involving drinking from bottles as a measure of taste aversion, rats had access to fluid (water, sucrose, or saccharin-glucose solution depending on the stage of the experiment, see "Experimental procedures") for $20 \mathrm{~min}$ each day starting the day before the beginning of the experimental procedure and throughout its whole duration. The use of such a fluid restriction protocol is common in CTA studies involving drinking from bottles and is justified by the need to ensure reproducible drinking during a given time interval (Wagner et al., 1981; Mackey et al., 1986; Blancquaert et al., 1987; Roldan and Bûres, 1994; Caulliez et al., 1996). Each rat was used only for one experiment, being killed within $24 \mathrm{hr}$ from completion of the extinction sessions.

All animal experimentation was conducted in accordance with the statement revised and approved by the Society for Neuroscience in January 1995 and with the guidelines for care and use of experimental animals of the European Commission (86/609; D.L.: 27.01.1992; number 116).

\section{Experimental procedures}

CTA, multiple trials (experiment 1). This procedure was performed for $10 \mathrm{~d}$ and consisted of three phases. In the first, baseline training phase (days 1-3), the animals were trained to drink a water solution of saccharin $(0.1 \%)$ plus glucose $(3 \%)$ for 20 min each day; the intake (milliliters per $20 \mathrm{~min}$ ) of this solution was recorded for each rat. At the end of this phase the animals were randomly assigned to the various experimental groups (saline + saline; SCH $233906.0,12.5,25.0$, and $50.0 \mu \mathrm{g} / \mathrm{kg}$, s.c. + saline; saline + lithium; and SCH $233906.0,12.5,25.0$, and $50.0 \mu \mathrm{g} / \mathrm{kg}$, s.c. + lithium). In the second, conditioning phase (days 4-6), the saccharin-glucose solution was presented each day for $20 \mathrm{~min}$, and its intake was recorded; the last drinking session before any exposure to lithium (i.e., trial on day 4) was taken as the trial session. All subsequent drinking sessions were considered as test sessions and were numbered as first (day 5), second (day 6), etc. Five minutes after each drinking session, animals were given saline or SCH 23390 subcutaneously and, after a further 30 min they received lithium chloride $(40 \mathrm{mg} / \mathrm{kg}$, i.p.) or saline. In the third, extinction phase (days 7-10), the saccharin-glucose solution was presented for 20 min every day, and the intake was recorded. Data are expressed as test per trial ratio (milliliters per milliliter) of saccharin intake [ratio of the saccharin intake on test i.e., $24 \mathrm{hr}$ after each pairing with lithium (days 5, 6 etc.) and that on the first day (day 4) of pairing with lithium (trial)].

$C T A$, single trials (experiments 2 and 3). In this procedure rats were trained to drink water for $20 \mathrm{~min}$ each day for $5 \mathrm{~d}$ (baseline training) and were conditioned by a single lithium-saccharin (plus 3\% glucose) association; thus, 5 min after the saccharin presentation (experiment 2) or 30 min before or at the start of saccharin presentation, 5 or 45 min after the end of saccharin presentation (experiment 3), rats received different doses of SCH $23390(6.0,12.5,25.0,50.0 \mu \mathrm{g} / \mathrm{kg}$, s.c.) or saline. One hour after saccharin, rats were administered with lithium chloride $(125 \mathrm{mg} / \mathrm{kg}$, i.p.) or with saline; the extinction phase lasted $3 \mathrm{~d}$ and consisted of three saccharin (plus $3 \%$ glucose) tests on the seventh, eighth, and ninth days. To evaluate the effect of D1 receptors in CTA learning using a different $\mathrm{CS}$, the above procedure was repeated using a $15 \%$ sucrose solution in tap water in place of the saccharin-glucose solution. In this case, doses of SCH 23390 (6.0 and $12.5 \mu \mathrm{g} / \mathrm{kg}$, s.c.) were used with the same protocol described for the saccharin-glucose experiments. In these experiments with sucrose as CS, the more specific $\mathrm{D}_{1}$ receptor antagonist $\mathrm{SCH} 39166$, an analog of $\mathrm{SCH} 23390$, or a $\mathrm{D}_{2}$ receptor antagonist (raclopride), were also tested with the same protocol used for SCH 23390.

Taste reactivity (experiment 4 ). The taste reactivity paradigm has been used to evaluate the hedonic impact of tastes by quantifying behavioral reactions elicited by intraoral infusion of solutions (Grill and Norgren, 1978). Here we have used as taste a sweet chocolate solution that elicited intense and clear-cut hedonic taste reactions. An oral catheter was inserted $24 \mathrm{hr}$ before the experimental session at the level of the first molar; polyethylene tubing was passed along the skull and fixed to it with glasionomeric cement (CX-Plus; Shofu, Tokyo, Japan). Each rat underwent a conditioning and an extinction session. On conditioning, a chocolate solution was pumped at a constant rate of $0.2 \mathrm{ml} / \mathrm{min}$ for a total amount of $1 \mathrm{ml}$. Five minutes after chocolate inf usion, rats were administered SCH $23390(25 \mu \mathrm{g} / \mathrm{kg}$, s.c. $)$ or saline. Fifty-five minutes after SCH 23390 rats received lithium chloride $(125 \mathrm{mg} / \mathrm{kg}$, i.p.). During chocolate infusion animals were videotaped, and three classes of affective taste reactivity patterns were scored: hedonic, aversive, and neutral. Hedonic reactions were: lateral tongue protrusions, rhythmic tongue protrusions, and paw licks; aversive reactions were: gapes, chin rubs, face washing, forelimb flails, paw tread, locomotion, and head dog shakes; neutral reactions were: rhythmic mouth movements and passive drip of the solution (Berridge and Robinson, 1998). Each lateral and rhythmic tongue protrusion, gape, chin rub, forelimb flail, and paw tread was counted as an individual event, and each event was assigned one point. Other events were assigned one point if the duration was between 1 and $5 \mathrm{sec}$ and 2 points if the duration was $>5 \mathrm{sec}$. On extinction sessions, 24 $\mathrm{hr}$ after conditioning, rats received an infusion of chocolate $(1 \mathrm{ml})$ at a constant rate of $0.2 \mathrm{ml} / \mathrm{min}$, and taste reactivity was evaluated.

Local intracerebral drug infusion (experiment 5). Under anesthesia (chloral hydrate $400 \mathrm{mg} / \mathrm{kg}$, i.p.) the animals were placed in the stereotaxic apparatus and bilaterally implanted with stainless steel guide cannulas in nucleus accumbens (NAc) shell [coordinates: anterior $(\mathrm{A})+2.0$, lateral (L) \pm 1.1 , ventral (V) -7.8$]$, in the NAc core (coordinates: A +1.5, $\mathrm{L} \pm 2.0, \mathrm{~V}-7.2$ ), in the lateral hypothalamic area (LHA) (coordinates: $\mathrm{A}-2.6, \mathrm{~L} \pm 2, \mathrm{~V}-8.4$ ), and in the bed nucleus stria terminalis (BNST) (coordinates: $\mathrm{A}-0.1, \mathrm{~L} \pm 1.1, \mathrm{~V}-7.6$ ) according to Paxinos and Watson (1998). The guide cannulas were cemented $5 \mathrm{~mm}$ above the aimed site of injection to prevent the injected solutions from leaking out of the cannulas. After a $3 \mathrm{~d}$ recovery, rats were trained to drink water, $20 \mathrm{~min}$ each day, for $5 \mathrm{~d}$ (training). On the sixth day (conditioning), the rats were given access to a $0.1 \%$ saccharin plus $3 \%$ glucose solution in tap water for $20 \mathrm{~min}$ in their home cage. The amount (in milliliters) of $0.1 \%$ saccharin (plus 3\% glucose) solution consumed after a 20 min session was recorded, and 5 or 45 min thereafter each rat was bilaterally microinjected with SCH 39166 or saline. For intracerebral drug inf usion, rats were held by hand, and stainless steel cannulas, connected with a $10 \mu$ l Hamilton syringe by polyethylene tubing, were carefully inserted into the guide cannula. A volume of $1 \mu \mathrm{l}$ was infused into the specific areas at a speed of $0.5 \mu \mathrm{l} / \mathrm{min}$. After completion of the infusion, the cannula was left in place for $1 \mathrm{~min}$; 55 or $15 \mathrm{~min}$ later rats received an intraperitoneal injection of a single dose ( 80 or $125 \mathrm{mg} / \mathrm{kg}$ ) of a $0.15 \mathrm{M}$ lithium chloride solution or of saline and were returned to their home cages. Twenty-four hours after, saccharin (plus 3\% glucose) was presented for $20 \mathrm{~min}$, and the volume consumed was recorded. Twenty-four hours after the last test animals were anesthetized with chloral hydrate $(400 \mathrm{mg} / \mathrm{kg}$, i.p.) and perfused transcardially with saline followed by $10 \%$ formaldehyde to verify the site of injection. Brains were cut coronally $(40 \mu \mathrm{m})$ with a vibratome (Series 1000; Technical Products International, St. Louis, $\mathrm{MO}$ ), and the cannula track was reconstructed. As described before, this procedure was also performed using a $15 \%$ sucrose solution in tap water. Data are expressed as test per trial ratio of fluid consumed.

Drugs and substances. Lithium chloride (Merck, Milan, Italy) was dissolved in water to make an isotonic solution $(0.15 \mathrm{M})$ and injected intraperitoneally in a volume of $1.7 \mathrm{ml}(40 \mathrm{mg} / \mathrm{kg}$, i.p.), $3.4 \mathrm{ml}(80 \mathrm{mg} / \mathrm{kg}$, i.p.), or $5.3 \mathrm{ml}(125 \mathrm{mg} / \mathrm{kg}$, i.p.). SCH 23390 (Research Biochemicals, Milan, Italy) was dissolved in saline solution and injected subcutaneously in a volume of $0.1 \mathrm{ml} / 100 \mathrm{gm}$ of body weight. SCH 39166 (Schering Plough, Milan, Italy) was dissolved in saline. Saccharin (Original Hermesetas, Bracco, Milan, Italy) and sucrose (Eridania, Genova, Italy) were dissolved in tap water. Chocolate syrup (Yoo-hoo; Yoo-hoo Chocolate Beverage Corporation, Carlsbad, NJ) contained: sucrose $40 \%$, corn syrup, water, cocoa, nonfat milk, salt, preservative E202, emulsifier E415, and artificial flavor and was infused intraorally as a 1:1 solution in tap water. Raclopride (Research Biochemicals) was dissolved in saline and injected subcutaneously in a volume of $0.1 \mathrm{ml} / 100 \mathrm{gm}$ of body weight.

\section{Statistics}

The significance of differences between groups was evaluated by one way, two-way or three-way ANOVA-MANOVA) and Tukey's post hoc test with significance set at $p<0.05$. 


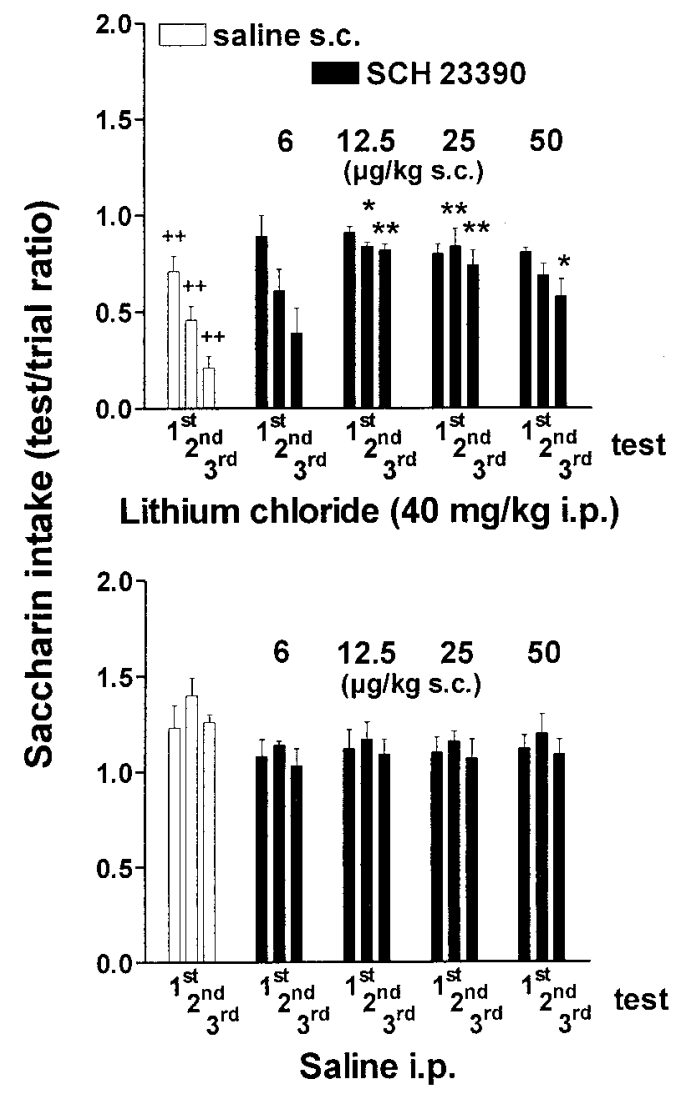

Figure 1. Effect of systemic SCH 23390 or saline on saccharin intake conditioned by multiple association with lithium chloride (top panel) or unconditioned (bottom panel). SCH 23390 was given subcutaneously 5 min after saccharin, whereas lithium chloride was given 30 min thereafter. Each bar represents the mean \pm SEM of test per trial ratio of saccharin intake in 20 min. ${ }^{+} p<0.05$ or ${ }^{++} p<0.005$ versus intraperitoneal saline; $* p<0.05$ or $* * p<0.005$ versus lithium.

\section{RESULTS}

\section{Effect of systemic SCH 23390 on multiple trials CTA (experiment 1)}

Figure 1 shows the development of CTA to saccharin induced by three saccharin-lithium associations as well as the effect of various doses of SCH $23390(6,12.5,25,50 \mu \mathrm{g} / \mathrm{kg}$, s.c.) given $5 \mathrm{~min}$ after saccharin in association with lithium or saline intraperitoneally (top panel). Three-way ANOVA revealed a significant effect of test days $\left(F_{(2,76)}=14.5 ; p<0.0001\right)$ and of lithium $\left(F_{(1,36)}=138.6 ; p<0.0001\right)$ and a significant test $\times$ lithium interaction $\left(F_{(2,76)}=11.3 ; p<0.0001\right)$. Post hoc analysis showed that saccharin intake was progressively reduced on test days after each saccharin-lithium association trial. A progressive recovery underwent on the extinction period that followed the last association with lithium (fourth, fifth, and sixth tests; data not shown). Post hoc analysis showed a maximal reduction of saccharin intake on the third test (Fig. 1), whereas on the sixth test saccharin intake had almost completely recovered (data not shown).

Three-way ANOVA also showed a significant interaction between SCH 23390 dose and lithium $\left(F_{(4,38)}=5.4 ; p<0.001\right)$. SCH 23390 did not exert significant effects on saccharin intake in the absence of lithium $\left(F_{(4,17)}=1.4 ; p=0.275\right.$ ) (Fig. 1, bottom panel). Post hoc analysis showed that SCH 23390 significantly reduced CTA at doses of 12.5, 25.0, and $50.0 \mu \mathrm{g} / \mathrm{kg}$ but not of 6 $\mu \mathrm{g} / \mathrm{kg}$, given subcutaneously, and that maximal impairment of

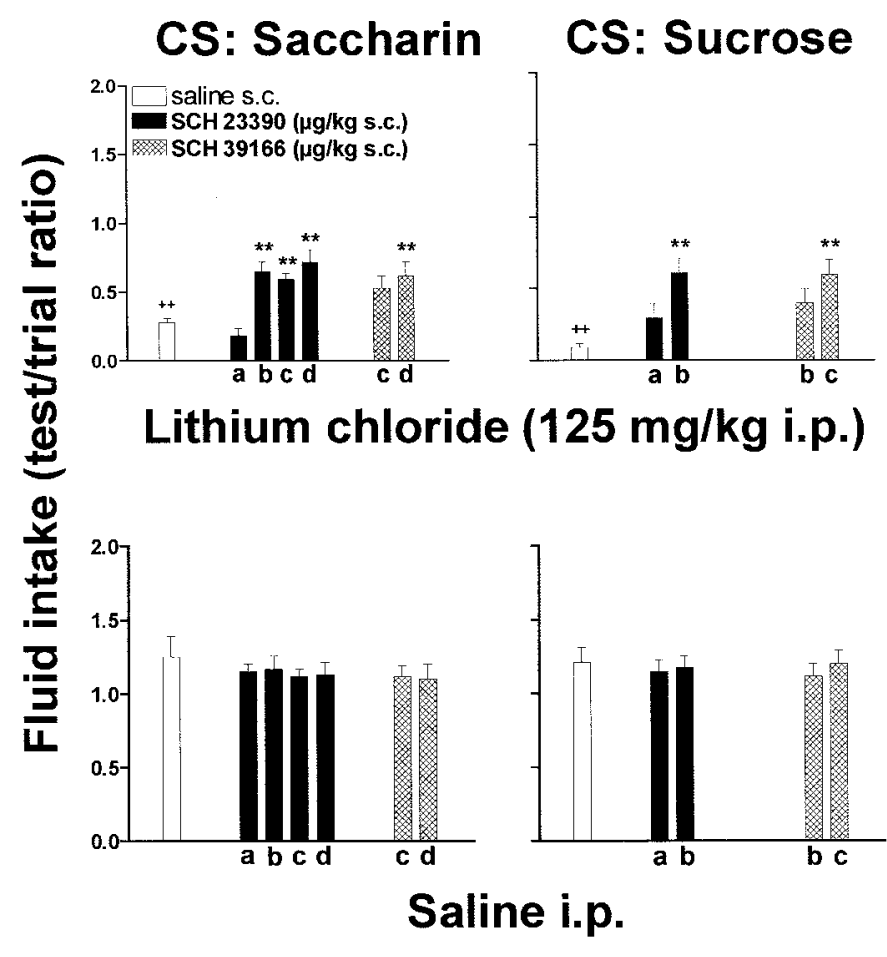

Figure 2. Effect of SCH 23390 and SCH 39166 on the intake of saccharin or sucrose either unconditioned or conditioned by lithium chloride. Each bar represents the mean \pm SEM of test per trial ratio of saccharin intake in $20 \mathrm{~min}$. $a$, $6.0 \mu \mathrm{g} / \mathrm{kg}$, s.c.; $b, 12.5 \mu \mathrm{g} / \mathrm{kg}$, s.c.; $c$, $25 \mu \mathrm{g} / \mathrm{kg}$, s.c.; $d, 50$ $\mu \mathrm{g} / \mathrm{kg}$, s.c. ${ }^{++} p<0.005$ versus intraperitoneal saline; ${ }^{*} p<0.05$ or ${ }^{* *} p<$ 0.005 versus lithium.

CTA was obtained at doses of $25 \mu \mathrm{g} / \mathrm{kg}$ of SCH 23390. Post hoc analysis also showed that higher doses of SCH $23390(50.0 \mu \mathrm{g} / \mathrm{kg})$ were less effective in impairing CTA than doses of 12.5 and 25 $\mu \mathrm{g} / \mathrm{kg}$ (Fig. 1, top panel).

Effect of systemic SCH 23390 and SCH 39166 on single-trial CTA (experiment 2)

The effect of SCH $23390(6,12.5,25,50 \mu \mathrm{g} / \mathrm{kg}$, s.c.) was also tested on single-trial CTA with saccharin as CS on a single association with lithium (125 mg/kg, i.p.), and the results are shown in Figure 2. Two-way ANOVA revealed a significant effect of lithium $\left(F_{(1,89)}=167.83 ; p<0.0001\right)$ and of $\mathrm{SCH}$ $23390\left(F_{(4,89)}=32.91 ; p<0.006\right)$ and a significant interaction between SCH 23390 dose and lithium $\left(F_{(4,89)}=6.50 ; p<0.0001\right)$. Post hoc tests showed a significant effect of doses of 12.5, 25, and $50 \mu \mathrm{g} / \mathrm{kg}$ of $\mathrm{SCH} 23390$, but not of $6.0 \mu \mathrm{g} / \mathrm{kg}$. A significant difference was observed between the lowest dose $(6.0 \mu \mathrm{g} / \mathrm{kg})$ and the doses of 12.5, 25.0, and $50.0 \mu \mathrm{g} / \mathrm{kg}$ of $\mathrm{SCH} 23390$ given subcutaneously. The effect on saccharin intake of the association between SCH 23390 and saccharin in the absence of lithium was also tested in a group of rats administered with SCH $233905 \mathrm{~min}$ after saccharin followed, $55 \mathrm{~min}$ later, by saline in place of lithium. Under these conditions SCH 23390 did not exert significant effects on saccharin intake $\left(F_{(4,17)}=0.71 ; p=0.59\right)$ (Fig. 2).

To exclude a role of $5-\mathrm{HT}_{2}$ receptors in the action of $\mathrm{SCH}$ 23390, the analog SCH 39166 (25 and $50 \mu \mathrm{g} / \mathrm{kg}$, s.c.), devoid of $5-\mathrm{HT}_{2}$ actions, was tested, and the results are shown in Figure 2. Two-way ANOVA revealed a significant interaction between SCH 39166 dose and lithium $\left(F_{(2,55)}=4.197 ; p<0.05\right)$. Post hoc tests showed a significant effect of the dose of $50 \mu \mathrm{g}$ (Fig. 2). Pairing of saccharin with SCH 39166 in the absence of lithium did 


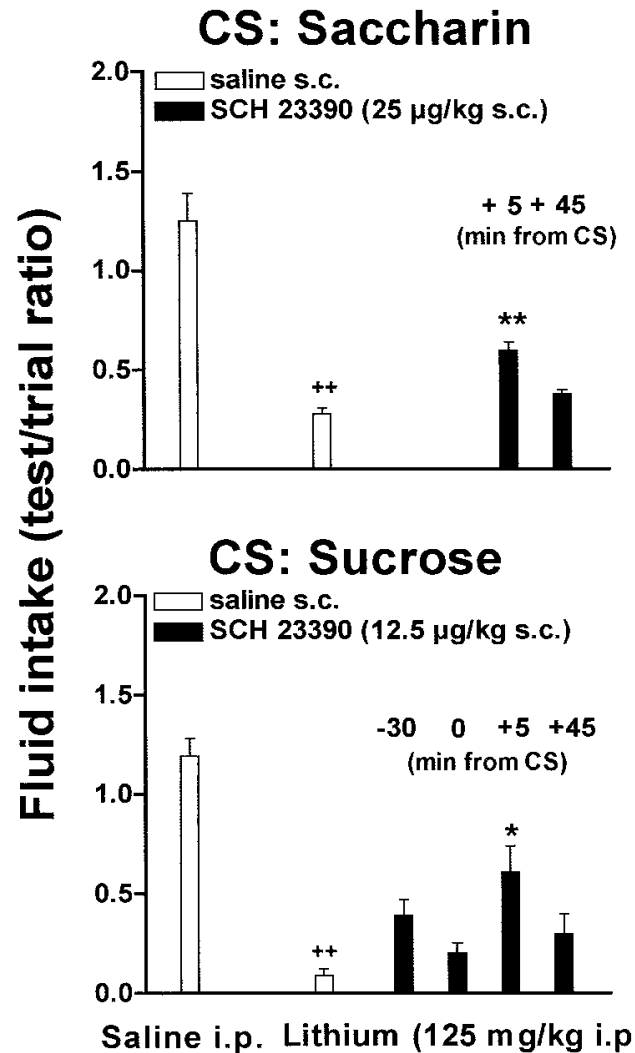

Figure 3. Effect of delay between systemic SCH 23390 and saccharin (top panel) or sucrose (bottom panel) on CTA learning. ${ }^{++} p<0.005$ versus intraperitoneal saline; ${ }^{* *} p<0.005$ versus lithium.

not exert any effect on saccharin intake $24 \mathrm{hr}$ later $\left(F_{(2,11)}=0.38\right.$; $p=0.69)$ (Fig. 2).

The effect of SCH 23390 (6 and $12.5 \mu \mathrm{g} / \mathrm{kg}$, s.c.) and SCH 39166 (12.5 and $25 \mu \mathrm{g} / \mathrm{kg}$, s.c.) on CTA learning was also studied using sucrose as CS, and the results are shown in Figure 2. Two-way ANOVA revealed a significant effect of lithium $\left(F_{(1,33)}=88.5 ; p<0.0001\right)$ and a significant interaction between SCH 23390 dose and lithium $\left(F_{(2,33)}=5.11 ; p<0.01\right)$. Post hoc analysis revealed that lithium $(125 \mathrm{mg} / \mathrm{kg}$, i.p.) induced a strong CTA also to sucrose. Two-way ANOVA also showed a significant interaction between SCH 39166 dose and lithium $\left(F_{(2,33)}=7.08\right.$; $p<0.005)$. Post hoc analysis revealed that SCH 39166 (12.5 and $25 \mu \mathrm{g} / \mathrm{kg}$, s.c.) reduced CTA to sucrose (Fig. 2). Pairing of sucrose with the $\mathrm{D}_{1}$ antagonists in the absence of lithium did not exert any significant effect on sucrose intake $24 \mathrm{hr}$ later $\left(F_{(4,17)}=\right.$ $0.91 ; p=0.48$; NS) (Fig. 2).

To investigate the role of $\mathrm{D}_{2}$ dopamine receptors on lithiuminduced CTA, the dopamine $\mathrm{D}_{2} / \mathrm{D}_{3}$ receptor antagonist raclopride was tested. Two-way ANOVA showed that raclopride (100 and $300 \mu \mathrm{g} / \mathrm{kg}$, s.c.) injected $5 \mathrm{~min}$ after sucrose intake failed to impair CTA induced by lithium chloride $\left(F_{(2,27}=1.89 ; p=0.17\right)$. Pairing of sucrose with raclopride in the absence of lithium did not change sucrose intake $24 \mathrm{hr}$ later $\left(F_{(2,11)}=0.60 ; p=0.56\right.$; NS; data not shown).

\section{Role of delay between CS presentation and systemic SCH 23390 (experiment 3)}

To investigate the mechanism of the effect of SCH 23390 on CTA learning, the drug was administered 5 or 45 min after saccharin at a dose of $25 \mu \mathrm{g} / \mathrm{kg}$. Figure 3 (top panel) reports the results obtained. Three-way ANOVA showed a significant effect of time $\left(F_{(1,72)}=6.27 ; p<0.05\right)$ and a significant interaction between the dose of SCH 23390 and lithium $\left(F_{(1,72)}=11.13 ; p<0.005\right)$. Post hoc analysis revealed that SCH $23390(25 \mu \mathrm{g} / \mathrm{kg}$, s.c. $)$ reduced lithium-induced CTA when given $5 \mathrm{~min}$, but not $45 \mathrm{~min}$, after saccharin.

In a second series of experiments using sucrose as $\mathrm{CS}, \mathrm{SCH}$ $23390(12.5 \mu \mathrm{g} / \mathrm{kg}$, s.c. $)$, was administered either $30 \mathrm{~min}$ before, at the same time, $5 \mathrm{~min}$, or $45 \mathrm{~min}$ after the presentation of the CS. Figure 3 (bottom panel) reports the results obtained. Three-way ANOVA showed a significant interaction between SCH 23390 dose and lithium $\left(F_{(1,69)}=8.33 ; p<0.005\right)$. Post hoc analysis showed that SCH 23390 was able to impair CTA learning only when administered 5 min after the presentation of the CS (Fig. 3, bottom panel).

\section{Effect of SCH 23390 on lithium-induced taste reactivity to chocolate (experiment 4)}

To evaluate if the impairment of lithium-induced CTA learning by SCH 23390 resulted in a reduction of the aversive properties of a taste after its association with lithium, the effect of SCH 23390 $(25 \mu \mathrm{g} / \mathrm{kg}$, s.c.) was evaluated in a taste reactivity paradigm using chocolate as CS. During conditioning sessions rats showed intense hedonic reactions to chocolate with virtually no aversive reactions (Fig. $4 A, A^{\prime}$ ). As shown in Figure $4, B$ and $B^{\prime}$, previous association with lithium resulted in strong aversive reactions to chocolate on tests $24 \mathrm{hr}$ later and virtually no hedonic reactions. One-way ANOVA revealed a significant effect of group $\left(F_{(1,7)}=\right.$ 5.74; $p=0.04)$. Post hoc analysis showed that SCH 23390, given during conditioning, resulted in a reduction of aversive reactions to chocolate and in the recovery of some hedonic reactions that were particularly evident at the beginning of the intraoral infusion (Fig. $4 B^{\prime}$ ).

\section{Effect of intracerebral SCH 39166 on single-trial CTA (experiment 5)}

To investigate the locus of action of systemic $\mathrm{D}_{1}$ blockade on CTA learning, SCH 39166 was inf used bilaterally in various brain areas, $5 \mathrm{~min}$ after exposure to the CS (saccharin or sucrose), followed, $55 \mathrm{~min}$ later, by saline or lithium chloride. Figure 5 shows the results obtained with saccharin as CS. Two-way ANOVA showed a significant effect of lithium in all groups (NAc shell, $F_{(1,38)}=108, p<0.0001$; NAc core, $F_{(1,19)}=336.22, p<$ 0.0001 ; LHA, $\left.F_{(1,16)}=441.25, p<0.0001\right)$. Two-way ANOVA also revealed a significant interaction between the dose of $\mathrm{SCH}$ 39166 infused in the NAc shell and lithium $\left(F_{(3,38)}=5.60 ; p<\right.$ 0.005). Post hoc analysis showed a significant effect of 25 and 50 ng, but not $10 \mathrm{ng}$ of SCH 39166. Two-way ANOVA further showed a significant interaction between SCH 39166 dose and lithium also when SCH 39166 (25 and $50 \mathrm{ng}$ ) was infused in the LHA $\left(F_{(2.16)}=6.71 ; p<0.05\right)$. No significant effect was observed when SCH 39166 was infused in the NAc core $\left(F_{(2,19)}=0.88\right.$; $p=0.42$ ) (Fig. 5, top panel). SCH 39166, as shown in Figure 5 (bottom panel), did not exert any significant effect on saccharin intake when injected in the NAc shell, NAc core, LHA, and BNST followed by saline in place of lithium $\left(F_{(8,23)}=1.19 ; p=0.35\right.$; NS).

The effect of intracerebral SCH 39166 was also investigated on CTA induced by a dose of lithium $(125 \mathrm{mg} / \mathrm{kg}$, i.p.); this dose induced a stronger CTA than lithium $80 \mathrm{mg} / \mathrm{kg}$, given intraperitoneally. Also in this case, two-way ANOVA showed a significant interaction between SCH 39166 dose and lithium $\left(F_{(2,24)}=23.43\right.$; $p<0.00001)$. As shown in Figure 5 (top panel) SCH 39166 (25 


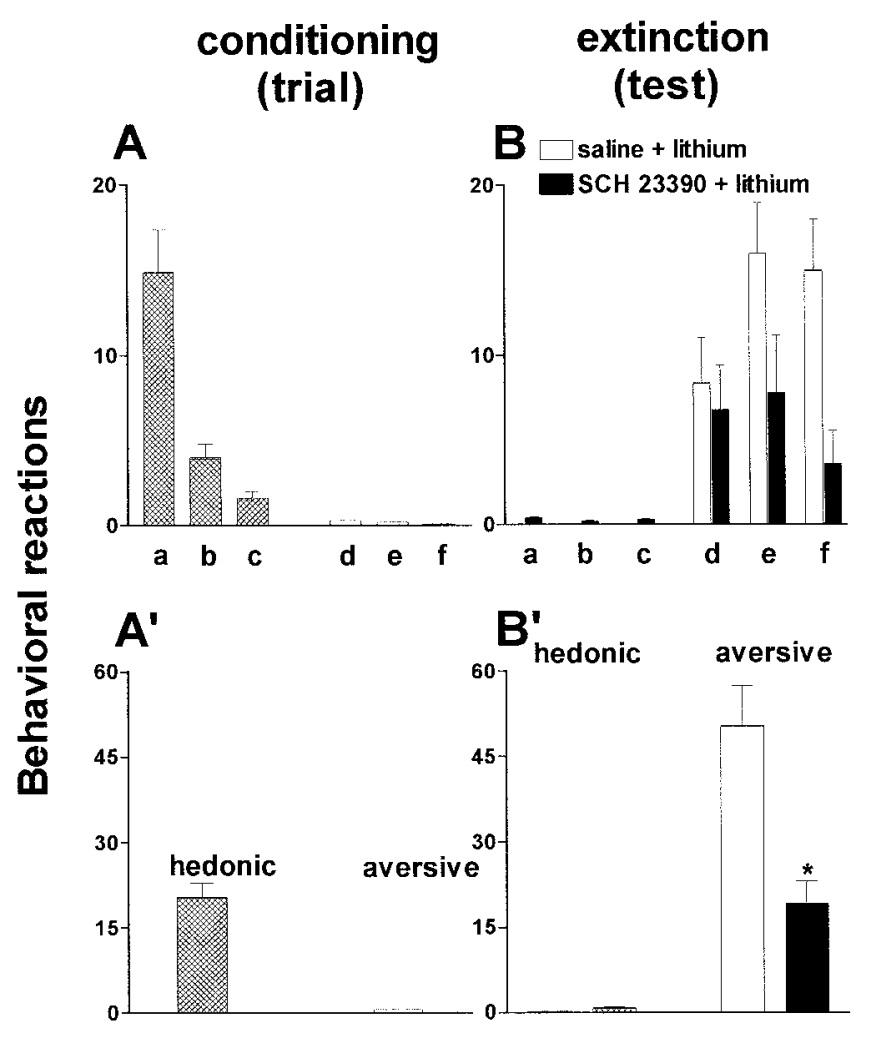

\section{Lithium chloride (125 mg/Kg i.p.)}

Figure 4. Effect of SCH $23390(25 \mu \mathrm{g} / \mathrm{kg}$, s.c. $)$ on the acquisition of aversive reactions to chocolate induced by a single association with lithium chloride $(125 \mathrm{mg} / \mathrm{kg}$, i.p.). Conditioning (trial): hedonic and aversive reactions to chocolate $\left(A\right.$, individual; $A^{\prime}$, total). Extinction (test): aversive and hedonic reactions to chocolate after saline (open bars) or SCH 23390 (filled bars) plus lithium ( $B$, individual; $B^{\prime}$, total). Each bar represents the means \pm SEM of hedonic and aversive reactions. $a$, Rhythmic tongue protrusion; $b$, sniffing; $c$, paw licks; $d$, gapes; $e$, chin rubs; $f$, paw tread. ${ }^{*} p<0.05$ versus subcutaneous saline.

and $50 \mathrm{ng}$ ) infused in the NAc shell reduced CTA induced by 125 $\mathrm{mg} / \mathrm{kg}$ lithium given intraperitoneally. It is notable that at the dose of $50 \mathrm{ng}$ the inhibition of lithium-induced CTA by $\mathrm{SCH}$ 39166 was close to being complete. No effect on CTA learning was observed when SCH 39166 was injected in the BNST.

These studies were duplicated using a $15 \%$ sucrose instead of a $0.1 \%$ saccharin solution as the CS. Also with sucrose as CS, SCH 39166 did not exert any significant effect on sucrose intake when injected alone into brain areas $\left(F_{(5,16)}=0.63 ; p=0.68\right.$; NS) (Fig. 6 , bottom panel). Two-way ANOVA revealed a significant effect of lithium in all groups (NAc shell, $F_{(1,36)}=273.52, p<0.00001$; NAc core, $F_{(1,14)}=147.69, p<0.00001$; LHA, $F_{(1,14)}=94.32$, $p<0.00001)$, and a significant interaction between SCH 39166 dose and lithium $\left(F_{(2,36)}=4.41 ; p<0.05\right)$. As shown in Figure 6 (top panel) SCH $39166(25,50$, and $100 \mathrm{ng} / \mu \mathrm{l})$ impaired CTA acquisition when infused in the NAc shell but not in the NAc core 5 min after sucrose. Post hoc analysis showed a significant effect of 50 and $100 \mathrm{ng}$, but not of $25 \mathrm{ng}$ of SCH 39166. Two-way ANOVA showed a significant interaction between SCH 39166 dose and lithium also when SCH 39166 was inf used in the $\operatorname{LHA}\left(F_{(1,14)}=\right.$ 7.07; $p<0.05$ ). SCH 39166 (50 ng) did not affect CTA learning when infused into the NAc shell 45 min after the presentation of $\mathrm{CS}\left(F_{(1,46)}=0.227 ; p=0.63\right.$; NS). Figure 7 shows the injection sites.

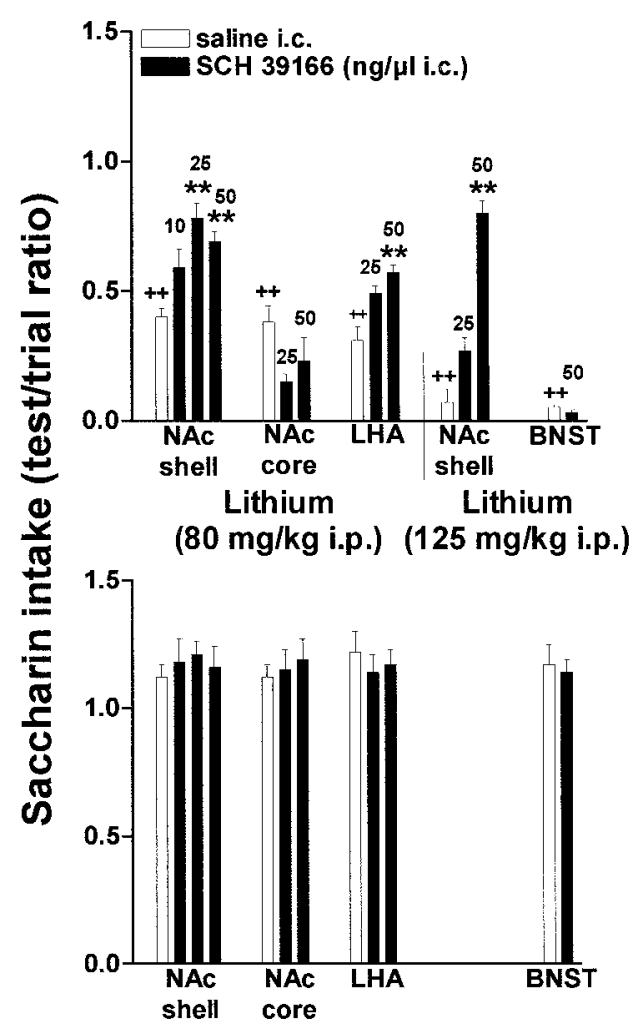

Saline i.p.

Figure 5. Effect of inf usion of SCH 39166 or saline in the NAc shell, NAc core, LHA, and BNST on saccharin intake conditioned by lithium chloride $(80$ or $125 \mathrm{mg} / \mathrm{kg}$, i.p; top panel) or unconditioned (bottom panel). Differences between groups were evaluated by two-way ANOVA followed by Tukey's post hoc test. ${ }^{++} p<0.005$ versus intraperitoneal saline; * $p<$ 0.05 or $* * p<0.005$ versus lithium.

\section{DISCUSSION}

The main findings of the present study are threefold: first, systemic administration of low doses of $\mathrm{DA} \mathrm{D}_{1}$ receptor antagonists impairs CTA learning; second, this effect takes place at a critical stage in the associative process between the gustatory CS and the US corresponding to the formation and consolidation of a shortterm memory trace of the gustatory CS; third, this action can be reproduced by placing low, nanogram amounts of SCH 39166 in the NAc shell and in the LHA, but not in the NAc core or in the BNST.

\section{Time-dependent impairment of CTA learning by $D_{1}$ receptor antagonists}

The present CTA study was initially intended to duplicate with a different paradigm our previous observation that $D_{1}$ receptor blockade impairs acquisition of place conditioning to rewarding and aversive drug stimuli (Acquas et al., 1989; Acquas and Di Chiara, 1994). For this reason we selected a CTA procedure involving three CS-US (saccharin-lithium) associations as in the place conditioning paradigm; also the dose of lithium $(40 \mathrm{mg} / \mathrm{kg})$ was the same previously used in our place conditioning studies (Acquas and Di Chiara, 1994). With this schedule, which resulted in a progressive development of CTA, SCH 23390 impaired CTA at very low doses $(12-50 \mu \mathrm{g} / \mathrm{kg}$, s.c.) even lower than those found to impair acquisition of place aversion to lithium (Acquas and Di Chiara, 1994).

In a second series of experiments we used a CTA procedure 


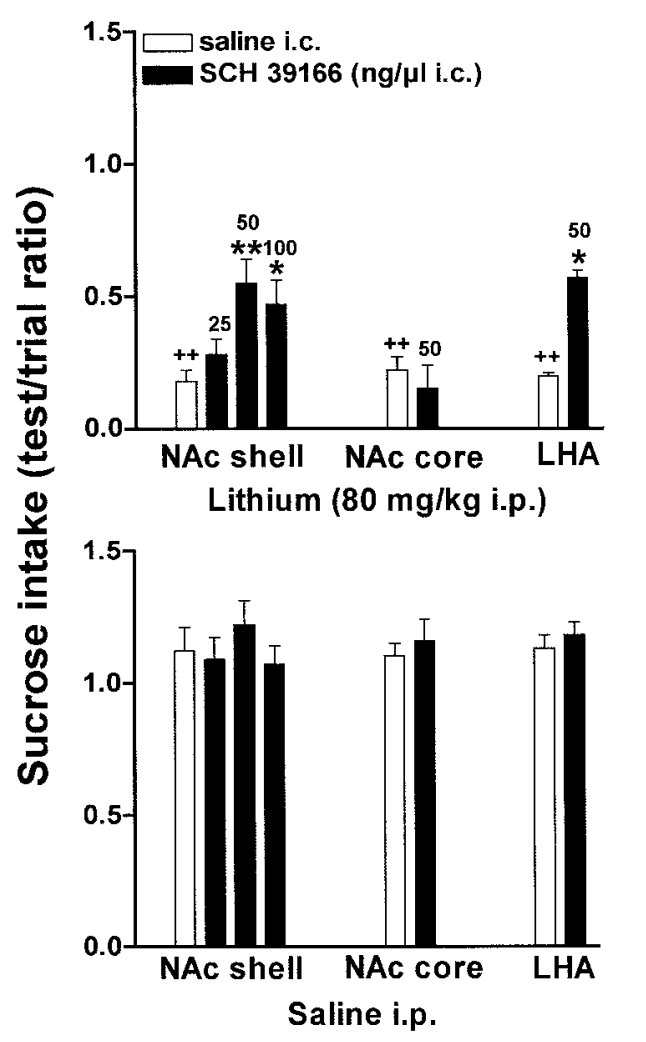

Figure 6. Effect of inf usion of SCH 39166 or saline in the NAc shell, NAc core, LHA, and BNST on sucrose intake conditioned by lithium chloride (80 or $125 \mathrm{mg} / \mathrm{kg}$, i.p.; top panel) or unconditioned (bottom panel). Differences between groups were evaluated by two-way ANOVA followed by Tukey's post hoc test. ${ }^{++} p<0.005$ versus saline; ${ }^{*} p<0.05$ or ${ }^{* *} p<$ 0.005 versus lithium.

involving a single association of saccharin or sucrose with a high dose of lithium in rats trained to drink tap water. Also under these conditions, low doses of SCH 23390 (12.5-50 $\mu \mathrm{g} / \mathrm{kg}$, s.c.) administered systemically impaired the acquisition of CTA. The more selective $\mathrm{D}_{1}$ antagonist SCH 39166 (Chipkin et al., 1988) exerted a similar effect at doses superimposable to those of $\mathrm{SCH}$ 23390 , in agreement with the similar in vivo potency of the two drugs as antagonists of $\mathrm{D}_{1}$ receptors. SCH 23390 not only reduced lithium-conditioned avoidance of sucrose or saccharin but also reduced the conditioned aversive properties of palatable taste stimuli in a taste reactivity paradigm. This observation indicates that SCH 23390 impaired the mechanism by which negative hedonic value is attributed to the taste, thus reducing the conditional aversive properties of the taste stimulus, rather than impairing its avoidance.

The present conclusions contrast with those of Berridge and Robinson (1998) who, on the basis of 6-hydroxy DA lesion studies, excluded that mesolimbic DA is involved in the acquisition of CTA as estimated by taste reactivity. At least two explanations can be offered for this discrepancy: first, that the lesions did not completely destroy the critical DA substrate in the NAc shell; second, that adaptive mechanisms taking place in non-DA neurons during the $8-17 \mathrm{~d}$ of postlesion recovery did compensate for any lesion-induced impairment.

SCH 23390 impaired CTA when given 5 min but not $45 \mathrm{~min}$ after the presentation of the CS (saccharin or sucrose) (i.e., 55 or 15 min, respectively, before lithium). Therefore, SCH 23390 did not impair CTA when the time course of its effect was superim-

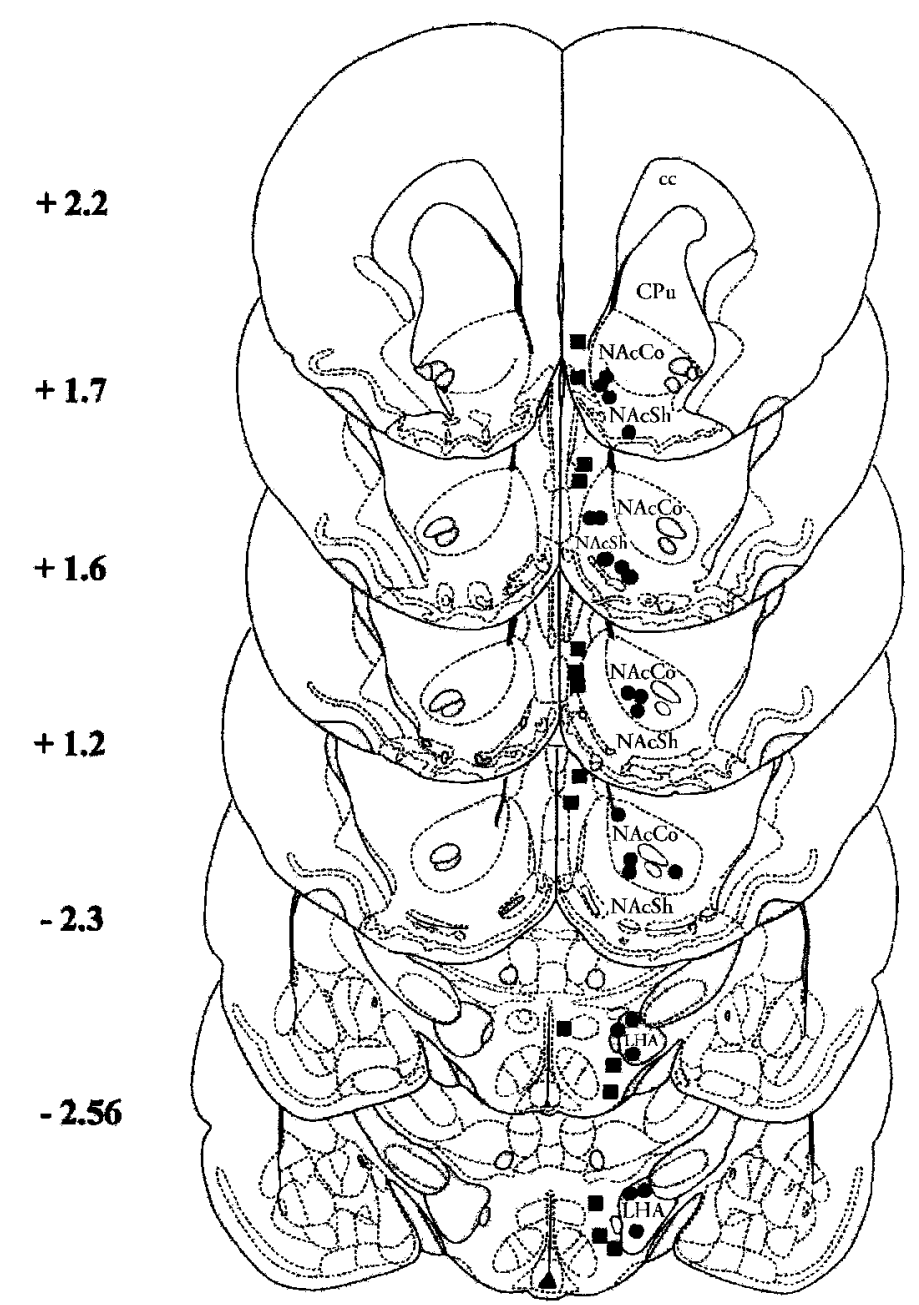

Figure 7. Brain sections showing intracerebral injection sites. Section levels are according to Paxinos and Watson (1999). Filled circles, Correct injection sites; filled squares, incorrect injection sites ( $c c$, corpus callosum; $C p u$, caudate putamen; NAc Sh, nucleus accumbens shell; NAc Co, nucleus accumbens core; $L H A$, lateral hypothalamic area).

posed to that of lithium. These observations exclude that the effect of SCH 23390 on CTA is related to an interference with the aversive properties of the US (lithium). On the other hand, $\mathrm{SCH}$ 23390 did not impair CTA when given $30 \mathrm{~min}$ before or at the start of the presentation of the taste CS, excluding that the effect of SCH 23390 given 5 min after drinking was attributable to an interference with some stimulus properties of the taste CS (aftertaste?). Finally, a nonspecific state-dependent mechanism (Overton, 1964) is excluded not only by the fact that both on trial and on test the CS was presented in the absence of the $D_{1}$ antagonist but also by the failure of a $\mathrm{D}_{2}$ antagonist to reproduce the effect of a $\mathrm{D}_{1}$ antagonist. The observation that the $\mathrm{D}_{1}$ antagonist impaired CTA given after taste trials but was ineffective if administered concurrently with the taste CS proves a fortiori that its effect is unrelated to a state-dependent mechanism.

According to Bûres et al. (1991), CTA is acquired through various phases: (1) initial processing of the taste stimulus; (2) formation and storage of a gustatory short-term memory trace; (3) association of the gustatory trace with the primary aversive (lithium) state (US); and (4) transfer of the CS-US association into a long-term memory store.

The observation that SCH 23390 impaired CTA when given 5 
min but not 45 min after the CS indicates that SCH 23390 acts on stage 2 , i.e., on the formation and storage of the gustatory shortterm memory trace. Blockade of $\mathrm{DA}_{1}$ receptors might accelerate the decay of the gustatory trace or, alternatively, impair its transfer to an area where association with the aversive state can take place. Therefore, endogenous DA acting on $\mathrm{D}_{1}$ receptors seems critical for the formation and consolidation of a gustatory short-term memory trace or for its transfer and storage into an area where can be associated with a visceral aversive state.

\section{Impairment of CTA learning by $D_{1}$ antagonist infusion in the nucleus accumbens shell}

Local intracerebral infusion of SCH 39166 shows that the NAc shell is critical for the effect of $\mathrm{D}_{1}$ blockade on CTA learning. This effect was site-specific because placements dorsal or lateral to the NAc shell in an area that includes the NAc core (Heimer et al., 1991) or in the BNST did not impair CTA learning. The effect of local $D_{1}$ receptor blockade in the NAc shell showed the same temporal properties of the systemic effect because it took place when SCH 39166 was inf used 5 min but not 45 min after the CS (see Results). In agreement with Caulliez et al. (1996), SCH 39166 impaired CTA when microinfused into the LHA.

A role of NAc shell in CTA learning is consistent with the fact that this area receives gustatory input from the agranular insular cortex and the basolateral amygdala and relays it to the parabrachial nucleus-nucleus tracti solitarii area (Heimer et al., 1991). The observation that the LHA shares with NAc shell a role in CTA acquisition is consistent with the existence of reciprocal connections between these areas (Heimer et al., 1991; Kirouac and Ganguly, 1995). Evidence for a facilitatory effect of $D_{1}$ receptor stimulation in the caudate on memory consolidation has been provided (Packard and White, 1991). In these studies, however, drugs were administered after the stimulus-reinforcer association had taken place, thus implicating consolidation of the CS-US association into long-term memory rather than consolidation of the short-term memory trace of the CS before its association with the US, as in the present study.

\section{Nucleus accumbens shell dopamine and gustatory learning}

The present observations might provide a role for the response properties of DA transmission in the NAc shell to unfamiliar tastes. According to Mark et al. (1991) intraoral saccharin increases DA release in the NAc before but decreases it after association with lithium. On the other hand, feeding of a novel palatable food stimulates DA release in the NAc shell, but this response undergoes one-trial habituation (Bassareo and Di Chiara, 1997) and is prevented by presentation of a predictive olfactory stimulus (Bassareo and Di Chiara, 1999). These properties are consistent with a role of phasic DA release in the NAc shell in associative gustatory learning. Thus, DA released on $\mathrm{D}_{1}$ receptors of the NAc shell by novel palatable tastes might act to modulate the efferent neurons of the shell in the processing of the gustatory stimulus after its perception. Therefore, DA release in the NAc shell might be the substrate of a consolidation mechanism by which a gustatory short-term memory trace is formed to remain available for enough long time to be associated with postingestive changes.

The mechanism of the influence of endogenous DA in CTA learning can account not only for the role of DA in aversive learning, as in the present study, but also in appetitive learning, as in the case of place preference (Acquas and Di Chiara, 1994; Di
Chiara, 1995). If, as suggested by the present study, DA affects associative learning by acting before the presentation of the US it might, depending on the valence of the US, exert its enabling action on either appetitive or aversive learning. Thus, the function of phasic DA release in the NAc rather than that of mediating the hedonic properties of rewards (Wise, 1982), might be that of facilitating the association between stimuli and their biological outcomes independently from the motivational valence of the outcome.

The observations of the present study might impact on issues beyond the strict boundaries of taste aversion learning. Thus, most drugs of abuse have been shown to increase, in a nonadaptive (nonhabituating) manner, DA transmission in the NAc shell (Di Chiara, 1998 and 1999). One might speculate that this action, by facilitating consolidation of drug-associated stimuli into shortterm memory, promotes the acquisition of conditional incentive properties by these stimuli that, after chronic drug exposure, come to control behavior in that excessive, compulsive manner that is typical of addiction (Di Chiara, 1998, 1999).

\section{REFERENCES}

Acquas E, Di Chiara G (1994) $D_{1}$ receptors blockade stereospecifically impairs the acquisition of drug-conditioned place-preference and place-aversion. Behav Pharmacol 5:555-569.

Acquas E, Carboni E, Leone P, Di Chiara G (1989) SCH 23390 blocks drug-conditioned place-preference and place-aversion: anhedonia (lack of reward) or apathy (lack of motivation) after dopamine-receptor blockade? Psychopharmacology 99:151-155.

Bassareo V, Di Chiara G (1997) Differential influence of associative and non associative learning mechanisms on the responsiveness of prefrontal and accumbal dopamine transmission to food stimuli in rats fed ad libitum. J Neurosci 17:851-861.

Bassareo V, Di Chiara G (1999) Modulation of feeding-induced activation of mesolimbic dopamine transmission by appetitive stimuli and its relation to motivational state. Eur J Neurosci 11:4389-4397.

Beninger RJ (1983) The role of dopamine in locomotor activity and learning. Brain Res Rev 6:173-196.

Berridge KC, Robinson TE (1998) What is the role of dopamine in reward: hedonic impact, reward learning, or incentive salience? Brain Res Rev 28:309-369.

Bindra D (1974) A motivational view of learning, performance and behavior modification. Psychol Rev 81:199-213.

Blancquaert JP, Lefebvre RA, Willems JL (1987) Antiaversive properties of opioids in the conditioned taste aversion test in the rat. Pharmacol Biochem Behav 27:437-441

Bûres J, Bûresova O, Ivanova SF (1988) Brain and behavior paradigms for research in neural mechanisms. Chichester, UK: Wiley.

Caulliez R, Meile MJ, Nicolaidis S (1996) A lateral hypothalamic $\mathrm{D}_{1}$ dopaminergic mechanism in conditioned taste aversion. Brain Res 729:234-245.

Chipkin RE, Iorio LC, Coffin VL, McQuade RD, Berger JC, Barnett A (1988) Pharmacological profile of SCH 39166: a dopamine $\mathrm{D}_{1}$ selective benzonaphtazepine with potential antipsychotic activity. J Pharmacol Exp Ther 247:1093-1102.

Di Chiara G (1995) The role of dopamine in drug abuse viewed from the perspective of its role in motivation. Drug Alcohol Depend 38:95-137.

Di Chiara G (1998) A motivational learning hypothesis of the role of dopamine in compulsive drug use. J Psychopharmacol 12:54-67.

Di Chiara G (1999) Drug addiction as dopamine-dependent associative learning disorder. Eur J Pharmacol 375:13-30.

Dickinson A, Balleine B (1994) Motivational control of goal-directed action. Anim Learn Behav 22:1-18.

Ehringer H, Hornykiewicz O (1960) Vereteilung for noradrenalin und dopamine (3-hydroxytiramine) im gebirn des menschen und ihr verbalten bei erkrangungen des extrapyramidalen system. Klin Wochenschr 38:1236-1239.

Epstein AN (1982) Instinct and motivation as explanations for complex behaviour. In: The physiology of motivation (Pfaff DW, ed), pp 25-58. New York: Springer.

Garcia J, Kimmeldorf DJ, Koelling RA (1955) Conditioned aversion to saccharin resulting from exposure to gamma radiation. Science 122:157-158.

Grill HJ, Norgren R (1978) The taste reactivity test: I. Mimetic responses to gustatory stimuli in neurologically normal rats. Brain Res 143:263-279.

Heimer L, de Olmos J, Alheid GF, Zaborszky L (1991) "Perestroika" in 
the basal forebrain: opening the border between neurology and psychiatry. Prog Brain Res 87:109-165.

Kirouac GJ, Ganguly PK (1995) Topographical organization in the nucleus accumbens of afferents from the basolateral amygdala and efferents to the lateral hypothalamus. Neuroscience 67:625-630.

Mackey WB, Keller J, Van Der Kooy D (1986) Visceral cortex lesions block conditioned taste aversion induced by morphine. Pharmacol Biochem Behav 24:71-78.

Mackintosh NJ (1983) Conditioning and associative learning. Oxford: Clarendon.

Mark GP, Blander DS, Hoebel BG (1991) A conditioned stimulus decreases extracellular dopamine in the nucleus accumbens after the development of a learned taste aversion. Brain Res 551:308-310.

Marshall JF, Teitelbaum P (1977) New considerations in the neuropsychology of motivated behaviours. In: Handbook of psychopharmacology, Vol 7 (Iversen LL, Iversen SD, Snyder SH, eds), pp 201-229. New York: Plenum.

Mogenson GJ, Jones DL, Yim CY (1980) From motivation to action: functional interface between the limbic system and the motor system. Prog Neurobiol 14:69-97.

Montague PR, Dayan P, Sejnowski TJ (1996) A framework for mesencephalic dopamine system based on predictive Hebbian learning. J Neurosci 16:1936-1947.

Overton DA (1964) State-dependent or "dissociated" learning produced with pentobarbital. J Comp Physiol Psychol 57:3-12.

Packard MG, White NM (1991) Dissociation of hippocampal and cau- date nucleus memory systems by post-training intracerebral injection of dopamine agonist. Behav Neurosci 105:295-306.

Paxinos G, Watson C (1998) The rat brain in stereotaxic coordinates. San Diego: Academic.

Roldan G, Bûres J (1994) Tetrodotoxin blockade of amygdala overlapping with poisoning impairs acquisition of conditioned taste aversion in rats. Behav Brain Res 65:213-219.

Salamone JD (1988) Dopaminergic involvement in activational aspects of motivation: effects of haloperidol on schedule-induced activity, feeding and foraging in rats. Psychobiology 16:196-206.

Salamone JD (1992) Complex motor and sensorimotor functions of striatal and accumbens dopamine: involvement in instrumental behavior processes. Psychopharmacology 107:160-174.

Toates F (1986) Motivational system. Cambridge, UK: Cambridge UP.

Wagner GC, Foltin RW, Seiden LS, Schuster CR (1981) Dopamine depletion by 6-hydroxydopamine prevents conditioned taste aversion induced by methylamphetamine but not lithium chloride. Pharmacol Biochem Behav 14:85-88.

Wise RA (1982) Neuroleptics and operant behavior: the anhedonia hypothesis. Behav Brain Sci 5:39-87.

Wise RA, Spindler J, Dewitt H, Gerber GJ (1978) Neuroleptic-induced "anhedonia" in rats: pimozide blocks reward quality of food. Science 201:262-264.

Yamamoto T, Shimura T, Sako N, Yasoshima Y, Sakay N (1994) Neural substrate for conditioned taste aversion in the rats. Behav Brain Res 65:123-137. 